editorial

\section{GOLD 2017}

Der neue Weg zur geeigneten Therapie bei COPD J. de Zeeuw, Köln

aufgefallen
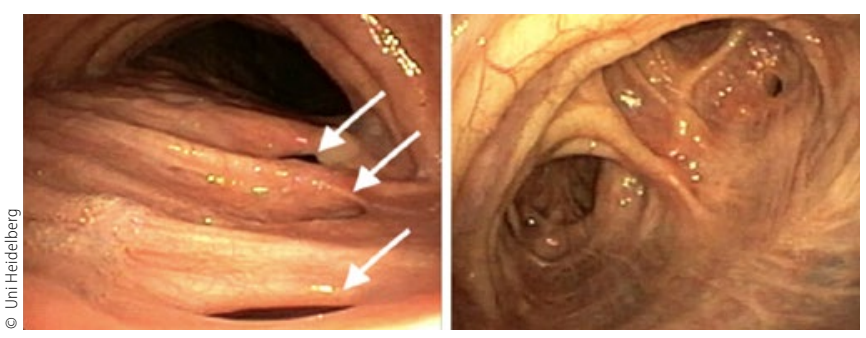

6 Selten und angeboren

Der Mann, der es leid war, krank zu sein

G. Grigaliûnas et al., Heidelberg

journal club

8 Übersicht der referierten Studien

Originalarbeit

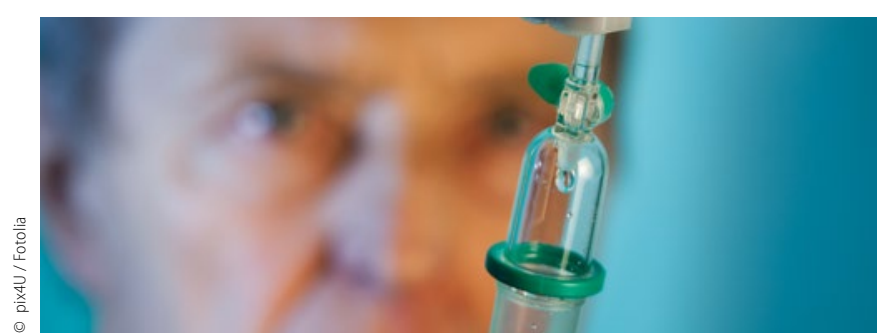

\section{COPD}

Outcomeprädiktoren für hospitalisierte COPD-Patienten

bei akuter Exazerbation

M. Spielmanns et al., Leverkusen zertifizierte fortbildung

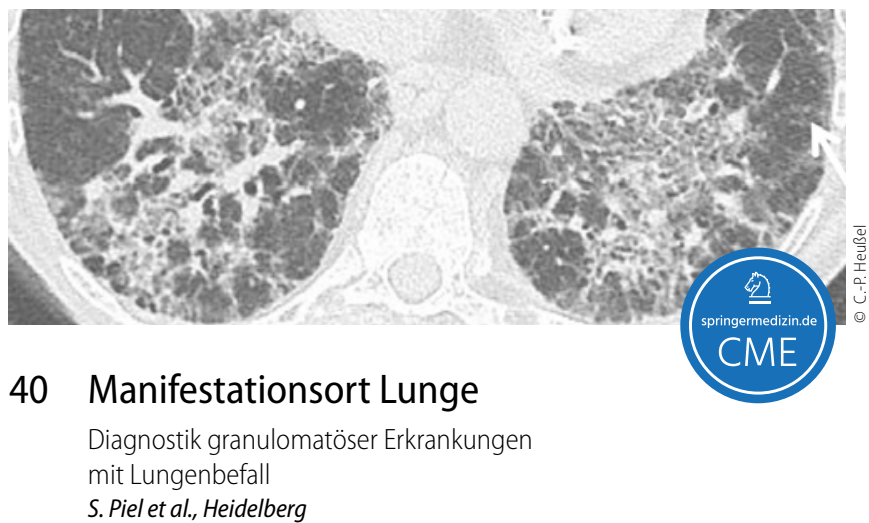

49 CME-Fragen granulomatöse Erkrankungen

aktuell

30 GOLD-Report 2017

„COPD-Therapie kann jetzt im Gespräch ermittelt werden“ Interview mit Prof. Claus Vogelmeier, Marburg

\section{Pneumo Update}

- Bronchiektasen: Prävalenz ist höher als gedacht

- Akute Exazerbationen: Ein Antibiotikum gehört bei COPD nicht zur Standardtherapie

- Kriterien für eine Lungentransplantation: Gesamtzustand des

Patienten sollte vor der OP berücksichtigt werden

- Neues zum Thema "Tuberkulose“: Bedarf an neuen

Tbc-Medikamenten

56 Spontanremission oder Fehldiagnose?

Viele „Asthmapatienten“ sind gar keine

\section{Zusammenhang entdeckt}

Wurst und Schinken sollen Asthma verstärken

rubriken

58 infopharm

59 impressum

\title{
Beihefter
}

\section{Pharmawissen aktuell:}

Nicht-Plattenepithelkarzinom der Lunge:

Nivolumab ist unabhängig vom PD-L1-Status ein neuer

Zweitlinienstandard $\mathbf{S} . \mathbf{5 2}$ 